\title{
ANALISIS KINERJA MINI FORKLIFT SEBAGAI ALAT BANTU ANGKAT DAN ANGKUT DENGAN BERBAGAI VARIASI BEBAN 300 - 500 KG PADA LAB TEKNIK MESIN UMT
}

\author{
Ali Rosyidin \\ Program Studi Teknik mesin, Fakultas teknik, Universitas Muhammadiyah Tangerang, \\ Jl. Perintis Kemerdekaan I, No.33, Cikokol, Tangerang, Banten 15118, Indonesia \\ E-mail: rosyidinali90@gmail.com
}

\begin{abstract}
Abstrak
Pada aktivitas angkat dan angkut termasuk aktivitas yang berat dan cenderung membutuhkan banyak tenaga kerja, selain itu aktivitas angkat dan angkut yang tidak menggunakan alat bantu sering terjadi kecelakaan yang berulang. MiniForklift merupakan salah satu alat angkat yang berfungsi sebagai alat bantu kerja proses angkat dan angkut. Mini Forklift memiliki beberapa bagian komponen utama antara lain rangka, garpu pengangkat, kait, puli, tali baja dan motor penggerak. Tujuan penelitan ini adalah untuk mengetahui kinerja MiniForklift dari hasil perhitungan tali baja dan analisa kekuatan menggunakan aplikasi autodesk inventor. Penelitian ini merupakan penelitian secara teoritis dari berbagai disiplin ilmu dan simulasi stress analysis pada inventor untuk mengetahui nilai kekuatan Mini Forklift agar terhindar dari kegagalan struktur. Pada hasil perhitungan tali baja nilai tegangan maksimum tali baja yaitu $601,79 \mathrm{~kg}$ dengan kekuatan putus tali sebenarnya yaitu 32444,79 $\mathrm{N}$ dan pada simulasi stress analysis aplikasi autodesk inventor didapatkan hasil tegangan maksimum vonmises $=83,4 \mathrm{MPa}$, 1st principal $=$ $50,53 \mathrm{MPa}$, 3rd principal $=5,34 \mathrm{MPa}$, dan defleksi $=1,8 \mathrm{~mm}$. dari hasil tegangan maksimum diatas diperoleh nilai safetyfactor 4,19 sehingga dapat disimpulkan Mini Forklift aman untuk digunakan karena nilai safety factor harus bernilai diatas 1 .
\end{abstract}

Kata kunci : tali baja, tegangan maksimum, simulasi stress analysis

\section{PENDAHULUAN}

Proses angkat dan angkut merupakan suatu aktivitas yang sering dilakukan saat melakukan berbagai kegiatan. Aktivitas tersebut membutuhkan tenaga yang cukup besar dan mempunyai resiko yang besar pula.Pada umumnya resiko yang sering dialami oleh pekerja angkat angkut adalah cedera tulang belakang. Salah satu konsep yang direncanakan pada alat bantu tersebut adalah mini forklift yaitu alat angkat angkut tersebut dapat dengan mudah digerakkan flexible sehingga alat tersebut dapat berfungsi secara optimal.

Mesin pemindah bahan (material handling equipment) adalah peralatan yang digunakan untuk memindahkan muatan yang berat dari satu tempat ke tempat lain dalam jarak yang tidak jauh, misalnya pada bagianbagian atau departemen pabrik, pada tempat-tempat penumpukan bahan, lokasi konstruksi, tempat penyimpanan dan pembongkaran muatan dan sebagainya. Mesin pemindah bahan hanya memindahkan muatan dalam jumlah dan besar tertentu dengan perpindahan bahan ke arah vertikal, dan atau kombinasi keduanya.

Mesin pemindah bahan (materials handling equipment) dapat dibagi dalam tiga kelompok, yaitu:

1. Peralatan permukaan dan overhead, yaitu peralatan yang ditujukan untuk memindahkan muatan curah dan satuan, baik batch maupun kontinu. 
2. Peralatan pengangkat, yaitu peralatan yang ditujukan untuk memindahkan muatan satuan dalam satu batch. Contohnya :Crane.

3. Peralatan pemindahan (conveyor), yaitu peralatan yang ditujukan untuk memindahkan muatan curah maupun muatan satuan secara kontinu.

Crane adalah alat yang digunakan untuk mengangkat dan memindahkan muatan dari satu tempat ketempat lain dengan menggunakan metode katrol dan kait (hook) sebagai pengaitnya. Crane sendiri banyak digunakan seperti pada bongkar muatan kapal-kapal di pelabuhan dan lainnya.Crane dapat diklasifikasikan kedalam beberapa jenis yaitu crane putar yang diam, crane yang bergerak pada rel, crane tanpa lintasan, crane yang dipasang pada lokomotif atau traktor rantai dan crane jembatan.

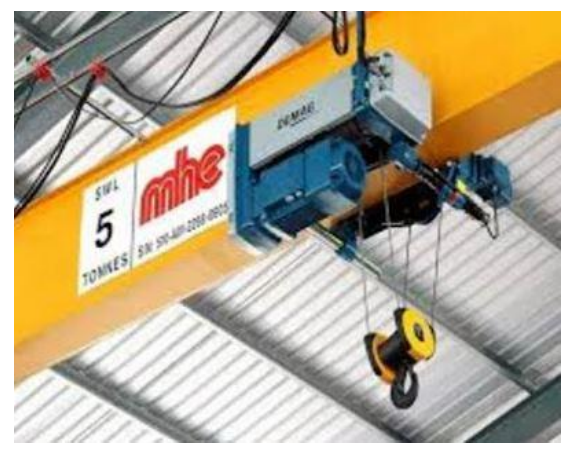

Gambar 1 . Hoist Crane

Hoist crane atau biasa disebut motor winch adalah salah satu dari klasifikasi jenis crane yang bergerak pada rel. Pesawat pengangkat yang biasanya terdapat pada pergudangan dan perbengkelan. Hoist crane ditempatkan pada langit-langit dan berjalan diatas rel khusus yang dipasangi pada langit-langit tersebut. Rel-rel tadi juga dapat bergerak secara maju mundur pada satu arah. Gerakan hoist crane ini adalah gerakan naik dan turun untuk mengangkat dan menurunkan muatan yang telah dijepit oleh spreader yang dikaitkan melalui tali baja yang digulung oleh drum, dimana drum ini digerakan oleh tenaga motor. Apabila posisi pengangkatnya telah disesuaikan seperti yang dikehendaki maka gerakan drum ini dapat dihentikan oleh rem (brake) yang dilakukan pada tombol switch. Tetapi pada kesempatan ini peneliti menempatkan hoist crane / motor winch dibagian belakang rangka pada alat mini forklift yang dibuat dengan fungsi yang sama seperti penjelasan diatas.

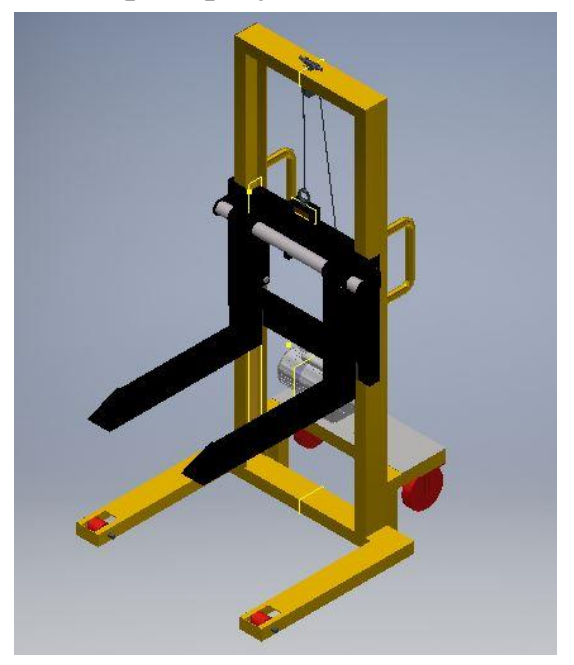

Gambar 2.Mini Forklift

Kabel baja berfungsi untuk mengangkat dan menurunkan beban serta mengatur kemiringan boom. Kabel baja adalah tali yang dikonstruksikan dari kumpulan jalinan serat-serat baja (steel wire) dengan kekuatan $\sigma \mathrm{b}=1300$ $2000 \mathrm{~N} / \mathrm{mm}^{2}$. Beberapa serat dipintal hingga menjadi satu jalinan (strand), 
kemudian beberapa strand dijalin pula pada suatu inti (core) sehingga membentuk tali. untuk menganalisa tegangan berat muatan yang akan diangkat maksimal harus ditentukan terlebih dahulu. Karena pada pengangkatan dipengaruhi oleh beberapa faktor, seperti berat trolley dan berat kait (hook), sehingga berat muatan yang diangkat dapat dibuat rumus sebagai berikut:

1. Diameter Rope

$435 d^{2}$.

Dimana :

$435 d^{2}$ : Kekuatan daya tarik tali $(\mathrm{N})$

$W$ : Kapasitas beban $(\mathrm{N})$

2. Diameter Wire

$d \mathrm{w}=0.063 d$

$A=0.38 d^{2}$.

Dimana :

$d \mathrm{w}=$ Diameter wire $(\mathrm{mm})$

$A:=$ Area wire rope $\left(\mathrm{mm}^{2}\right)$

3. Berat pada tali

$w=0.0363 d^{2}$

Dimana : $w$ : Berat pada tali (N)

4. Nilai Bending stress

$\begin{aligned} \sigma \mathrm{b} & =\frac{E r x d w}{D} \\ w b & =\sigma b x A\end{aligned}$

Dimana :

$\sigma \mathrm{b}=$ Nilai bending $\left(\mathrm{N} / \mathrm{mm}^{2}\right)$

$E r=$ Modulus elastisitas 84

$\mathrm{kN} / \mathrm{mm}^{2}$

$w b$ : Beban bending pada tali $(\mathrm{N})$

5. Beban efektif saat tali bekerja normal

Nilai $=W+w+w b$

6. Berat muatan yang diangkat

$\mathrm{Qm}=\mathrm{Q} 0+(10 \% \times \mathrm{Qo}) \ldots(2.7)$

Dimana :

$\mathrm{Qm}=$ Berat muatan yang diangkat $(\mathrm{N})$

Qo = Berat muatan yang telah ditentukan $(\mathrm{N})$

7. Kapasitas total yang diangkat $\mathrm{Q}=\mathrm{Qm}+\mathrm{Q}$ trolley $+\mathrm{Q}$ hook

Dimana :

$\mathrm{Q}=$ Kapasitas total yang

$$
\begin{gathered}
\text { diangkat }(\mathrm{kg}) \\
\mathrm{Qm}=\text { Berat muatan yang } \\
\text { diangkat }(\mathrm{N}) \\
\text { Qtrolley }=\text { Berat } \text { trolley }(\mathrm{kg})
\end{gathered}
$$

8. Tegangan maksimum dari sistem tali puli

$$
S=\frac{Q}{n \cdot \eta \cdot \eta 1}
$$

Pemilihan puli yang digunakan adalah puli tetap.

dimana :

$\mathrm{S}=$ Tegangan maksimum pada tali $(\mathrm{kg})$

$\mathrm{Q}=$ Kapasitas total yang diangkat $(\mathrm{kg})$

$\mathrm{n}=$ Jumlah puli yang digunakan sebagai penumpu

$\eta=$ Efisiensi puli $=0,951$ (dilihat dari tabel)

$\eta 1=$ Efisiensi yang disebabkan kerugian tali akibat kekuatan ketika menggulung pada drum yang diasumsikan 0,98

4. Kekuatan putus tali sebenarnya

$$
\mathrm{P}=\mathrm{S} . \mathrm{k} \text {. }
$$

Dimana :

$\mathrm{P}=$ Kekuatan putus tali $(\mathrm{kg})$

$\mathrm{S}=$ Tegangan pada tali $(\mathrm{kg})$

$\mathrm{k}=$ Faktor keamanan $(5,5$ dilihat dari tabel)

Autodesk Inventor merupakan program yang dirancang khusus untuk keperluan bidang teknik seperti desain produk, desain mesin, desain mold, desain konstruksi, atau keperluan teknik lainnya.Autodesk Inventor juga mampu memberikan simulasi pergerakan dari produk yang didesain serta mempunyai alat untuk menganalisis kekuatan. Alat ini cukup mudah digunakan dan dapat membantu untuk mengurangi kesalahan dalam membuat desain.

Setiap material pasti memiliki beban, dimana beban merupakan salah satu sifat fisik dari material. Sifat fisik dari material ini akan menimbulkan suatu gaya atau berat dari material 
tersebut. Beban operasional adalah beban yang timbul akibat adanya gerakan dan operasi dari material tersebut, seperti beban yang timbul akibat putaran yang akan menghasilkan torsi dan lain-lain.

\section{METODE PENELITIAN}

Metode penelitian yang digunakan adalah perhitungan manua tali baja berdasarkan study literature dan simulasi stress analysis autodesk inventor.

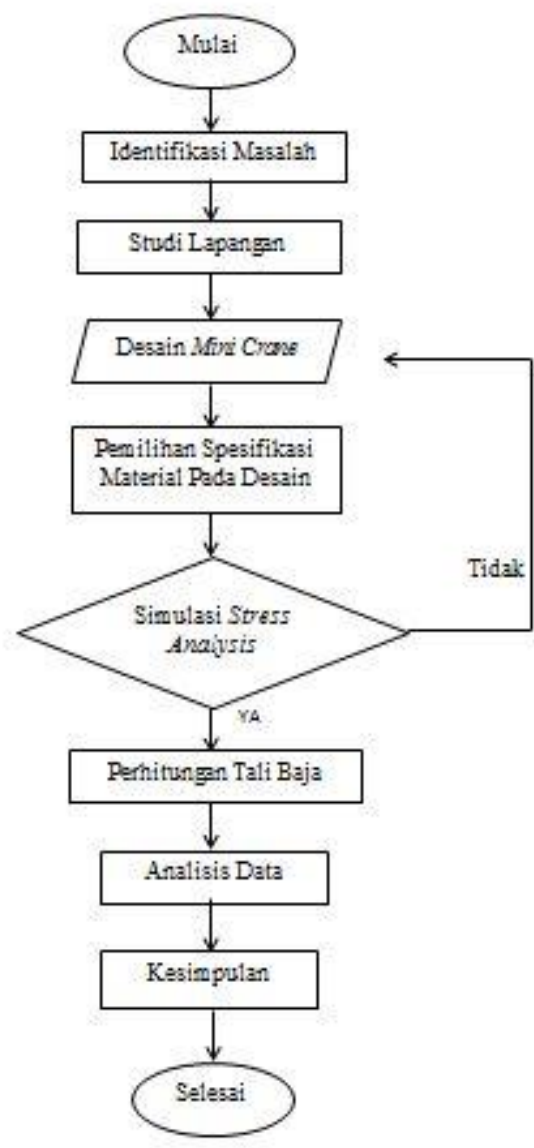

\section{Gambar 3. Diagram alir penelitian}

\section{HASIL DAN PEMBAHASAN}

Tali baja yang dipilih berbahan fiber core / inti serat baja dengan diameter 4,5 mm. Konstruksi tali baja yang digunakan yaitu 6 × 19 Analisa perhitungan akan dilakukan dengan berbagai variasi kinerja mini forklift 300 , 400 dan $500 \mathrm{~kg}$.

\section{Tabel 1. Hasil perhitungan tali} baja

\begin{tabular}{|c|c|c|c|}
\hline $\begin{array}{c}\text { Variasi } \\
\text { Beban }\end{array}$ & $\begin{array}{c}\text { Kapasitas } \\
\text { Beban } \\
\text { yang } \\
\text { Diangkat }\end{array}$ & $\begin{array}{c}\text { Tegangan } \\
\text { Maksimum } \\
\text { Tali Puli }\end{array}$ & $\begin{array}{c}\text { Kekuatan } \\
\text { Putus Tali } \\
\text { Sebenarnya }\end{array}$ \\
\hline $\begin{array}{c}300 \\
\mathrm{~kg}\end{array}$ & $341 \mathrm{~kg}$ & $\begin{array}{c}365,88 \\
\mathrm{~kg}\end{array}$ & $\begin{array}{c}19721,34 \\
\mathrm{~N}\end{array}$ \\
\hline $\begin{array}{c}400 \\
\mathrm{~kg}\end{array}$ & $451 \mathrm{~kg}$ & $\begin{array}{c}483,91 \\
\mathrm{~kg}\end{array}$ & $\begin{array}{c}26083,07 \\
\mathrm{~N}\end{array}$ \\
\hline 500 & $561 \mathrm{~kg}$ & $\begin{array}{c}601,94 \\
\mathrm{~kg}\end{array}$ & $\begin{array}{c}32444,79 \\
\mathrm{Ng}\end{array}$ \\
\hline
\end{tabular}

Dari tabel hasil perhitungan tali baja diatas, angka tertinggi terdapat pada variasi beban $500 \mathrm{~kg}$ yang menghasilkan tegangan maksimum tali baja $601,94 \mathrm{~kg}$ dan kekuatan putus tali sebenarnya $32444,94 \mathrm{~N}$.

Kemungkinan terjadinya kegagalan struktur pada mini forklift pada saat mengangkat beban maka dilakukan analisa menggunakan simulasi stress analysis yang ada pada autodesk inventor. Simulasi stress analysis akan dilakukan dengan berbagai variasi beban kinerja mini forklift 300, 400 dan $500 \mathrm{~kg}$. Hasil dari simulasi stress analysis akan didapatkan hasil tegangan von misses, tegangan 1st principal, tegangan 3rd principal, defleksi dan safety factor.

Kemudian memilih spesifikasi material sesuai desain yang dibuat sebelum memulai simulasi stress analysis. Berikut spesifikasi material yang digunakan : 
Tabel 2. Spesifikasi material

\begin{tabular}{|l|l|l|l|}
\hline \multicolumn{2}{|c|}{ Nama } & $\begin{array}{l}\text { Steel } \\
\text { Carbo } \\
n\end{array}$ & $\begin{array}{l}\text { Iron } \\
\text { Cast }\end{array}$ \\
\hline \multirow{4}{*}{ General } & $\begin{array}{l}\text { Massa } \\
\text { Jenis }\end{array}$ & $\begin{array}{l}7,85 \\
\mathrm{~g} / \mathrm{cm}^{3}\end{array}$ & $\begin{array}{l}7,15 \\
\mathrm{~g} / \mathrm{cm}^{3}\end{array}$ \\
\cline { 2 - 4 } & $\begin{array}{l}\text { Teganga } \\
\text { n Luluh }\end{array}$ & $\begin{array}{l}350 \\
\mathrm{MPa}\end{array}$ & $\begin{array}{l}758 \\
\mathrm{MPa}\end{array}$ \\
\cline { 2 - 4 } & $\begin{array}{l}\text { Kekuata } \\
\text { n Tarik }\end{array}$ & $\begin{array}{l}420 \\
\mathrm{MPa}\end{array}$ & $\begin{array}{l}884 \\
\mathrm{MPa}\end{array}$ \\
\hline \multirow{4}{*}{$\begin{array}{l}\text { Teganga } \\
\mathrm{n}\end{array}$} & $\begin{array}{l}\text { Modulus } \\
\text { Elastis }\end{array}$ & $\begin{array}{l}200 \\
\mathrm{GPa}\end{array}$ & $\begin{array}{l}120,5 \\
\mathrm{GPa}\end{array}$ \\
\cline { 2 - 4 } & $\begin{array}{l}\text { Konstant } \\
\text { a Elastis }\end{array}$ & $0,29 \mathrm{ul}$ & $0,3 \mathrm{ul}$ \\
\cline { 2 - 4 } & $\begin{array}{l}\text { Modulus } \\
\text { Geser }\end{array}$ & $\begin{array}{l}77,519 \\
4 \mathrm{GPa}\end{array}$ & $\begin{array}{l}46,346 \\
1 \mathrm{GPa}\end{array}$ \\
\hline
\end{tabular}

Pada stress analysis ditentukan kondisi operasi dengan simulasi beban sebesar 300 - $500 \mathrm{~kg}$ pada garpu pengangkat dan memberi fixed constraint sebagai titik pegangan atau tumpuan beban.

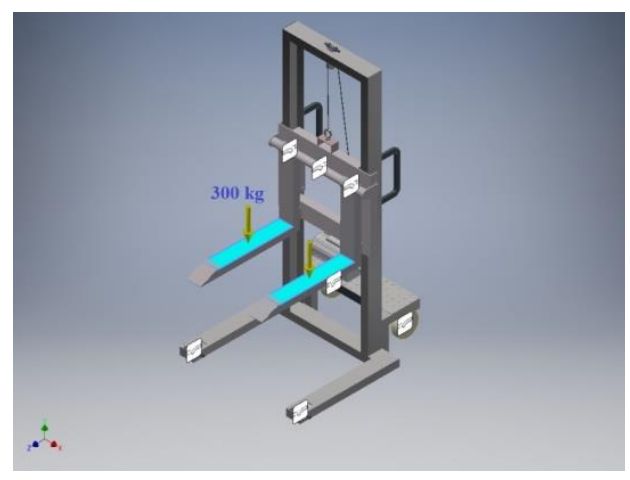

Gambar 4. Simulasi beban

Tabel 3. Hasil analisa stress analysis

\begin{tabular}{|l|l|l|}
\hline Nama & Minimum & Maksimum \\
\hline Volume & $20090500 \mathrm{~mm}^{3}$ \\
\hline
\end{tabular}

\begin{tabular}{|c|c|c|}
\hline \multirow{2}{*}{\begin{tabular}{l|} 
Massa \\
Tegangan \\
Von \\
Mises \\
\end{tabular}} & \multicolumn{2}{|l|}{$116,08 \mathrm{~kg} \mathrm{~kg}$} \\
\hline & $0 \mathrm{MPa}$ & $83,4179 \mathrm{MPa}$ \\
\hline $\begin{array}{l}\text { Tegangan } \\
1 \text { st } \\
\text { Principal }\end{array}$ & $-32,1522 \mathrm{MPa}$ & $50,5324 \mathrm{MPa}$ \\
\hline $\begin{array}{l}\text { Tegangan } \\
\text { 3rd } \\
\text { Principal }\end{array}$ & $-89,4805 \mathrm{MPa}$ & 5,34816 MPa \\
\hline Defleksi & $0 \mathrm{~mm}$ & $1,80537 \mathrm{~mm}$ \\
\hline $\begin{array}{l}\text { Faktor } \\
\text { Keamana } \\
\mathrm{n}\end{array}$ & 4,19574 & 15 \\
\hline $\begin{array}{l}\text { Tegangan } \\
\text { XX }\end{array}$ & $-33,4832 \mathrm{MPa}$ & $12,6702 \mathrm{MPa}$ \\
\hline $\begin{array}{l}\text { Tegangan } \\
\text { XY }\end{array}$ & $-26,5449 \mathrm{MPa}$ & 20,1841 MPa \\
\hline $\begin{array}{l}\text { Tegangan } \\
\mathrm{XZ}\end{array}$ & $-15,6276 \mathrm{MPa}$ & $16,6878 \mathrm{MPa}$ \\
\hline $\begin{array}{l}\text { Tegangan } \\
\text { YY }\end{array}$ & $-84,9013 \mathrm{MPa}$ & $39,8658 \mathrm{MPa}$ \\
\hline $\begin{array}{l}\text { Tegangan } \\
\text { YZ }\end{array}$ & $-28,0873 \mathrm{MPa}$ & $24,2664 \mathrm{MPa}$ \\
\hline $\begin{array}{l}\text { Tegangan } \\
\mathrm{ZZ}\end{array}$ & $-81,4098 \mathrm{MPa}$ & $35,1618 \mathrm{MPa}$ \\
\hline $\begin{array}{l}\text { Defleksi } \\
\text { X }\end{array}$ & $\begin{array}{l}-0,0940202 \\
\mathrm{~mm}\end{array}$ & $\begin{array}{l}0,0901765 \\
\mathrm{~mm}\end{array}$ \\
\hline $\begin{array}{l}\text { Defleksi } \\
\text { Y }\end{array}$ & $-1,78075 \mathrm{~mm}$ & $0.069489 \mathrm{~mm}$ \\
\hline $\begin{array}{l}\text { Defleksi } \\
\mathrm{Z}\end{array}$ & $\begin{array}{l}-0,294013 \\
\mathrm{~mm}\end{array}$ & $\begin{array}{l}0,0768733 \\
\mathrm{~mm}\end{array}$ \\
\hline $\begin{array}{l}\text { Reganga } \\
\mathrm{n} \\
\text { Equivale } \\
\mathrm{n}\end{array}$ & 0 & 0.000373049 \\
\hline $\begin{array}{l}\text { Reganga } \\
\mathrm{n} \quad 1 \mathrm{st} \\
\text { Principal }\end{array}$ & $\begin{array}{l}- \\
0,0000017680 \\
2\end{array}$ & 0,000267872 \\
\hline $\begin{array}{l}\text { Reganga } \\
\mathrm{n} \quad 3 \mathrm{rd} \\
\text { Principal }\end{array}$ & $-0,000427047$ & $\begin{array}{l}0,0000045229 \\
5\end{array}$ \\
\hline Reganga & $-0,000142412$ & 0,000148003 \\
\hline
\end{tabular}




\begin{tabular}{|l|l|l|}
\hline$n$ XX & & 0,000130187 \\
\hline $\begin{array}{l}\text { Reganga } \\
\text { n XY }\end{array}$ & $-0,000171215$ & 0,000107636 \\
\hline $\begin{array}{l}\text { Reganga } \\
\text { n XZ }\end{array}$ & $-0,000100798$ & 0,000188202 \\
\hline $\begin{array}{l}\text { Reganga } \\
\text { n YY }\end{array}$ & $-0,000401494$ & 0,000156518 \\
\hline $\begin{array}{l}\text { Reganga } \\
n \text { YZ }\end{array}$ & $-0,000181163$ & 0,000167092 \\
\hline $\begin{array}{l}\text { Reganga } \\
\text { n ZZ }\end{array}$ & $-0,000291434$ & $226,513 \mathrm{MPa}$ \\
\hline $\begin{array}{l}\text { Kontak } \\
\text { Tekan }\end{array}$ & $0 \mathrm{MPa}$ & $37,6056 \mathrm{MPa}$ \\
\hline $\begin{array}{l}\text { Kontak } \\
\text { Tekan X }\end{array}$ & $-28,0748 \mathrm{MPa}$ \\
\hline $\begin{array}{l}\text { Kontak } \\
\text { Tekan Y }\end{array}$ & $-134,154 \mathrm{MPa}$ & $169,164 \mathrm{MPa}$ \\
\hline $\begin{array}{l}\text { Kontak } \\
\text { Tekan Z }\end{array}$ & $-152,236 \mathrm{MPa}$ & $114,969 \mathrm{MPa}$ \\
\hline
\end{tabular}

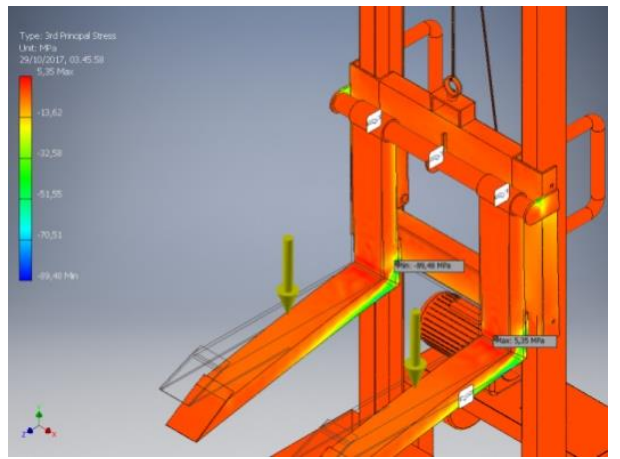

\section{Gambar 7. Tegangan $3^{\text {rd }}$ Principal}

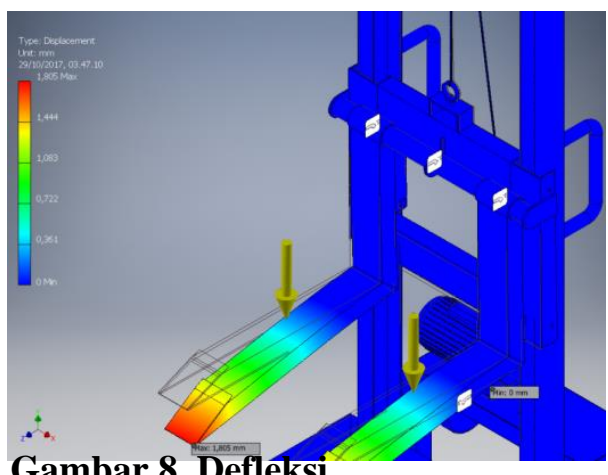

Gambar 8. Defleksi

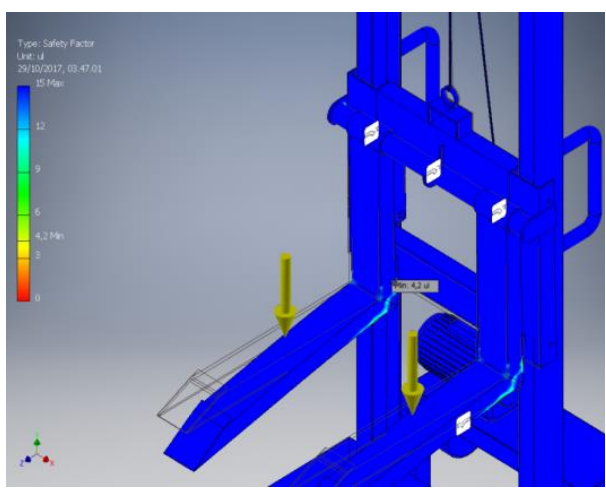

\section{Gambar 9. Safety Factor}

Material dikatakan mulai luluh ketika tegangan VonMises atau tegangan luluh mencapai nilai kritis yang diketahui sebagai yield strength. Tegangan maksimum 1st Principal yang menunjukkan secara spesifik bagian 
yang paling tegang, warna merah merupakan bagian yang paling tegang. Nilai tegangan 3rd Principal yang menunjukkan secara spesifik bagian yang paling rileks, warna kuning merupakan bagian yang paling rileks. Hasil analisa simulasi stress analysis menghasilkan nilai safety factor yang menunjukkan bagian yang aman ketika diberi gaya, bagian yang paling aman adalah bagian yang berwarna biru tua.

\section{KESIMPULAN}

Berdasarkan hasil analisis kinerja miniforklift dengan berbagai variasi beban 300, 400 dan $500 \mathrm{~kg}$ maka dapat disimpulkan beberapa hal sebagai berikut:

1. Dari analisis perhitungan tali baja dengan variasi beban $300 \mathrm{~s} / \mathrm{d} 500 \mathrm{~kg}$ didapatkan hasil perhitungan sebagai berikut :

1). Pada saat beban $300 \mathrm{~kg}$, tegangan maksimum tali puli $=365,88 \mathrm{~kg}$ dan kekuatan tali putus sebenaarnya $=19721,34 \mathrm{~N}$.

2). Pada saat beban $400 \mathrm{~kg}$, tegangan maksimum tali puli $=483,91 \mathrm{~kg}$ dan kekuatan tali putus sebenarnya $=26083,07 \mathrm{~N}$.

3). Pada saat beban $500 \mathrm{~kg}$, tegangan maksimum tali puli $=601,94 \mathrm{~kg}$ dan kekuatan tali putus sebenarnya $=32444,79 \mathrm{~N}$.

4). Setelah diketahui hasil perhitungan tali baja, maka dapat disimpulkan tali baja aman untuk digunakan karena beban yang diangkat masih dalam batas standar spesifikasi tali baja pada mini forklift yang diizinkan.

2. Dari simulasi stress analysis mini forklift yang dilakukan dengan setiap variasi beban $300 \mathrm{~s} / \mathrm{d} 500 \mathrm{~kg}$ didapatkan nilai hasil tegangan maksimum von mises (tegangan luluh), 1st principal, 3rd principal, defleksi dan safety factor sebagai berikut :

1). Hasil tegangan maksimum von mises dengan beban $300 \mathrm{~kg}=$ $50,2 \mathrm{MPa}, 400 \mathrm{~kg}=66,7 \mathrm{MPa}$ dan $500 \mathrm{~kg}=83,4 \mathrm{MPa}$.

2). Hasil tegangan maksimum 1 st Principal dengan beban 300 $\mathrm{kg}=30,28 \mathrm{MPa}, 400 \mathrm{~kg}=$ $40,42 \mathrm{MPa}$ dan $500 \mathrm{~kg}=$ $50,53 \mathrm{MPa}$.

3). Hasil tegangan maksimum 3rd Principal dengan beban 300 $\mathrm{kg}=3,21 \mathrm{MPa}, 400 \mathrm{~kg}=4,28$ $\mathrm{MPa}$ dan $500 \mathrm{~kg}=5,34 \mathrm{MPa}$.

4). Hasil tegangan maksimum defleksi dengan beban $300 \mathrm{~kg}$ $=1,08 \mathrm{~mm}, 400 \mathrm{~kg}=1,44 \mathrm{~mm}$ dan $500 \mathrm{~kg}=1,8 \mathrm{~mm}$.

5). Nilai safety factor pada saat beban $300 \mathrm{~kg}=6,97,400 \mathrm{~kg}$ $=4,24$ dan $500 \mathrm{~kg}=4,19$.

6). Setelah diketahui nilai safety factor tersebut, maka dapat disimpulkan mini forklift aman untuk digunakan karena nilai safety factor yang dianjurkan harus bernilai diatas 1.

\section{DAFTAR PUSTAKA}

1. Achmad Zainun., "Elemen Mesin 1", Yogyakarta : Penerbit Refika Aditama, 2013.

2. Asroni., "Stress Analysis Pada Stand Shock Absorber Sepeda Motor dengan Menggunakan Software Inventor 2015",Jurnal teknik mesin, Lampung, 2015, hal 23-27, Volume 4 Nomor 1.

3. Endi Sutanto dan Soeharsono, "Prancangan Gantry Crane Kapasitas 10 Ton Dengan Bantuan Software", Poros, 
Jakarta, Mei 2014, hal 80-86, Volume 2 Nomor 1.

4. Huda F Yon., "Autodesk Inventor Professional 2011 Panduan Mudah Merancang Mesin", Yogyakarta : Penerbit Andi,2012.

5. Hutahaean Yohanes Ramses. "Mekanika Kekuatan Materia"l Tingkat lanjut, Yogyakarta : Graha ilmu 2014.

6. Hutahaean Yohanes Ramses., "Mekanisme dan Dinamika Mesin", Edisi Revisi, Yogyakarta : Penerbit Andi, 2010.

7. Ngadiyono, Yatin, "Pembelajaran Autodesk Inventor", Yogyakarta, Indonesia : Fakultas Teknik Universitas Negeri Yogyakarta.

8. Riski Setiawan et al.], "Perancangan Portable Crane Kapasitas Angkat Maksimal 500 kg", E-Jurnal Teknik Mesin, Yogyakarta,Juni 2014, hal 27-32, Volume 2 Nomor 1.

9. Rudenko, N., "Mesin Pemindah Bahan", Terjemahan Foead, Nazar, Jakarta, Indonesia : Penerbit Erlangga,1992.

10. Scribd - Modul Training Inventor $-2011$

11. https://pt.scribd.com/mobile/doc/1 25897598/Modul-Training-

Inventor

12. Slide Share - Tutorial Inventor 2009 : Stress Analysis

13. https://www.slideshare.net/mobile zzulfabidin9/tutorial-inventor2009-stress analysis-17198555

14. Zainuri Muhib Ach., "Mesin Pemindah Bahan”, Yogyakarta: Penerbit Andi, 2010. 